\title{
Oral Mucocele Removal in a Pediatric Patient Using Diode Laser: A Case Report
}

\author{
Ruchika Sharma ${ }^{1}$, Nitin Khuller ${ }^{2}$
}

\begin{abstract}
Mucocele is a commonly occurring lesion in the oral cavity, mostly involving the minor salivary glands, resulting from the rupture or obliteration of the ducts leading to their glandular contents (mucinous) being released subepithelially. Etiological factors include trauma, parafunctional habits, lip-biting, etc. Various treatment modalities have been advocated for mucocele among which lasers are the most recent and advanced. This case report presents the treatment of mucocele of the lower lip with a $980 \mathrm{~nm}$ diode laser.

Keywords: Diode laser, Mucocele, Ranula, Salivary Gland.

Journal of Oral Health and Community Dentistry (2021): 10.5005/jp-journals-10062-0118
\end{abstract}

\section{BACKGROUND}

The term mucocele is derived from the Latin words mucus and coele meaning mucus in the cavity. Mucocele is a common salivary gland disorder, which is defined as a mucus-filled cyst that usually appears in the oral cavity, paranasal sinuses, or lacrimal sac. ${ }^{1}$ The lower labial mucosa is the most common site of involvement, but it may develop at virtually any location where minor salivary glands occur, including the soft palate, retromolar region, and buccal mucosa. Ranula is an accumulation of saliva on the floor of the mouth, so named because of its nodular bluish color (or buccal membrane of similar color, depending on the depth of the lesion) that resembles the aerated vocal sac of a frog. ${ }^{2,3}$ The incidence rate is high, and it is the second most commonly occurring lesion after irritational fibroma in the oral cavity. ${ }^{4}$ Clinically, mucocele is a few millimeters to centimeters, painless, and fluctuant, and imparts a transparent-to-bluish hue. The etiology of these lesions is related to mechanical trauma causing the rupture of the duct and extravasation of mucus into the surrounding tissue or due to the obstruction of the duct causing ductal expansion. ${ }^{5}$ Histologically, mucoceles are of two types: (a) extravasation type and (b) retention type. The extravasation cyst is usually seen in minor salivary glands and forms due to the leakage of fluids from the salivary gland ducts and acini into the surrounding soft tissue whereas the retention-type cyst results from the obstruction of the salivary gland duct and hence is commonly found in ducts of the major salivary glands. ${ }^{6}$ However, clinically, there is no difference in the two cyst types. As mucocele has high recurrence rate, various treatment approaches have been made like surgical, cryosurgical, intralesional corticosteroids, marsupialization, micromarsupialization, and lasers. ${ }^{7}$ Different kinds of lasers are available with varying wavelengths and absorption coefficients. Diode lasers are absorbed by melanin and hemoglobin due to this property and can precisely cut, coagulate, ablate, or vaporize the target soft tissue. Diode lasers are easy to move and handle as they do not have water or air lines. Lasers causes less trauma, improved healing, and faster recovery time when compared with conventional methods. ${ }^{8}$

In this case, mucocele of the lower lip was treated with a diode laser and the results are presented.

\begin{abstract}
1,2Department of Periodontology and Oral Implantology, Dasmesh Institute of Research and Dental Sciences, Faridkot, Punjab, India

Corresponding Author: Nitin Khuller, Department of Periodontology and Oral Implantology, Dasmesh Institute of Research and Dental Sciences, Faridkot, Punjab, India, Phone: +91 8054443227, e-mail: nkhuller@yahoo.com

How to cite this article: Sharma R, Khuller N. Oral Mucocele Removal in a Pediatric Patient Using Diode Laser: A Case Report. J Oral Health Comm Dent 2021;15(3):149-151.
\end{abstract}

Source of support: Nil

Conflict of interest: None

\section{Case Description}

A 6-year-old male patient reported to the Department of Periodontology and Oral Implantology with the chief complaint of presence of swelling on the left side of his lower lip since 3-4 weeks. Ethical clearance was taken from the ethical committee of the Dasmesh Institute of Research and Dental Sciences, Faridkot, Punjab. The treatment plan was explained and written informed consent was obtained from the patient's guardian. The medical history was noncontributory. The general examination did not reveal any abnormality. On intraoral examination, swelling was present on the left lower labial mucosa, approximately $1 \mathrm{~cm}$ in diameter with round-to-oval shape, soft, painless, fluid filled, reddish-blue in color, with a well-defined border, and nontender. The patient has the habit of biting his lower lip. Based upon the signs and symptoms, a clinical diagnosis of oral mucocele of the lower lip was made.

\section{Procedure}

After giving adequate local anesthesia (LA), complete excision of the lesion was made with the help of a diode laser, $980 \mathrm{~nm}$ (DCLase dental diode laser, DC International, USA). The lesion was excised under LA at $0.8-1.2 \mathrm{~W}$ in continuous mode and the charred tissue was removed gently with cotton dipped in saline in between the procedure to minimize the heat produced in the local area. A pressure pack was given after the procedure and the patient was recalled after 1 week.

() The Author(s). 2021 Open Access This article is distributed under the terms of the Creative Commons Attribution 4.0 International License (https://creativecommons. org/licenses/by-nc/4.0/), which permits unrestricted use, distribution, and non-commercial reproduction in any medium, provided you give appropriate credit to the original author(s) and the source, provide a link to the Creative Commons license, and indicate if changes were made. The Creative Commons Public Domain Dedication waiver (http://creativecommons.org/publicdomain/zero/1.0/) applies to the data made available in this article, unless otherwise stated. 


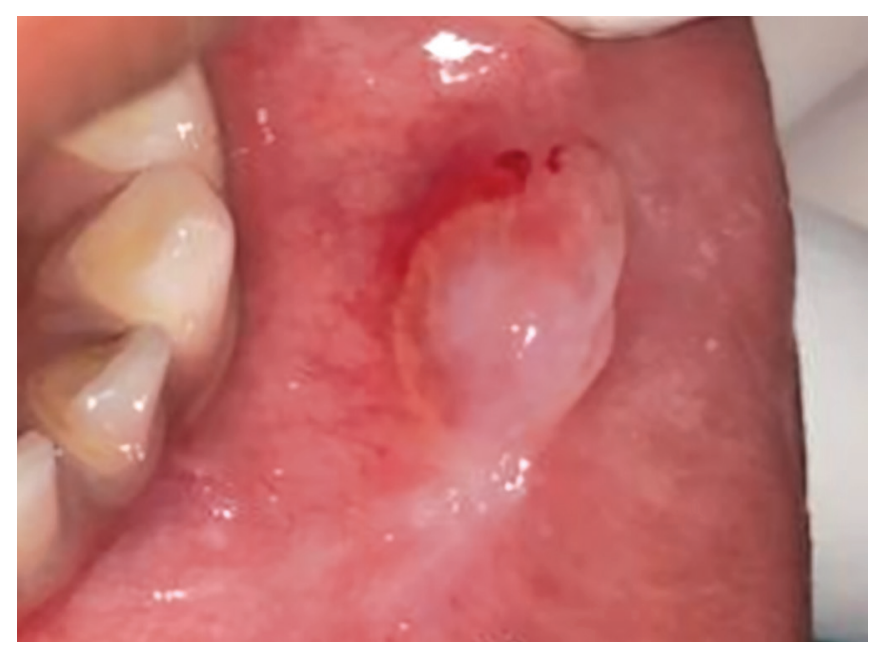

Fig. 1: Preoperative

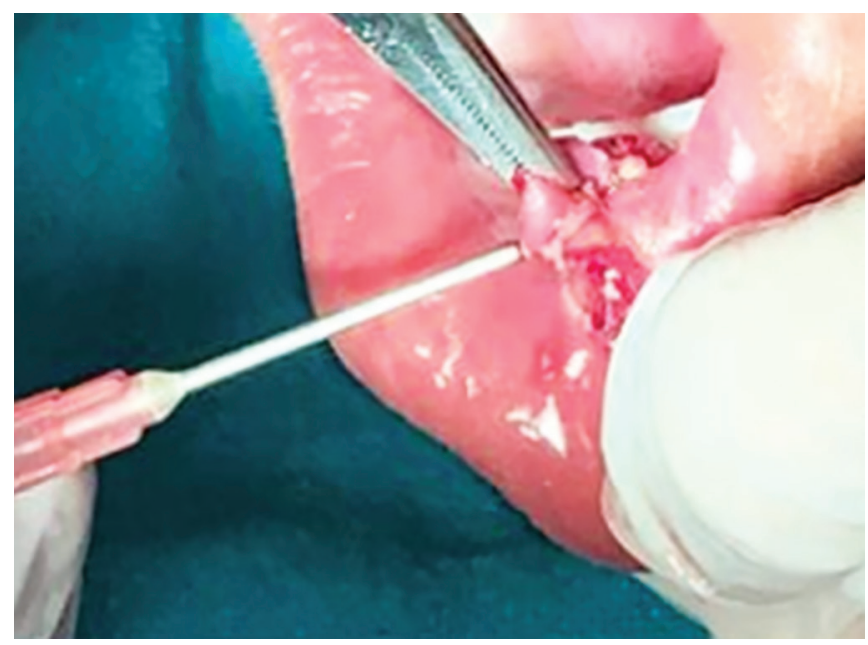

Fig. 2: Excision of mucocele using a diode laser

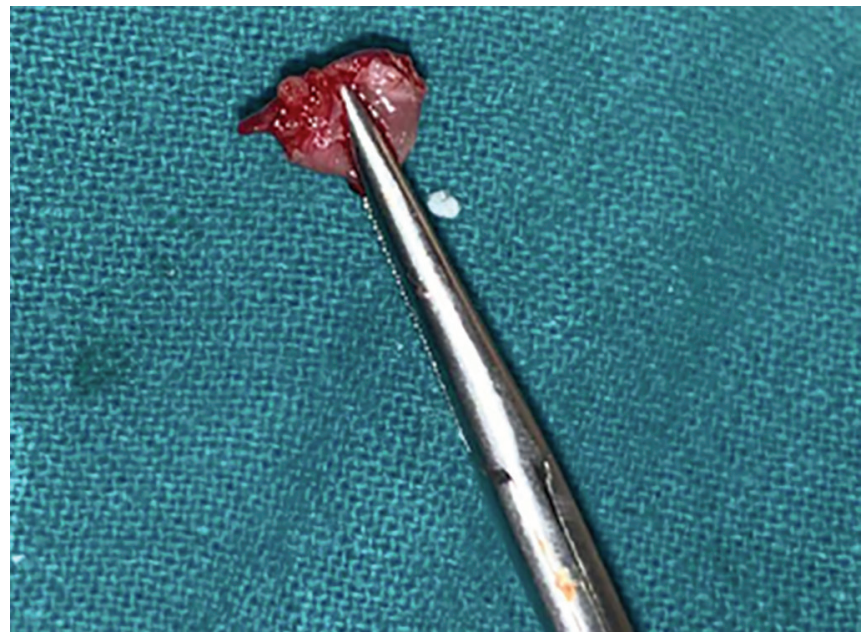

Fig. 3: Excised tissue

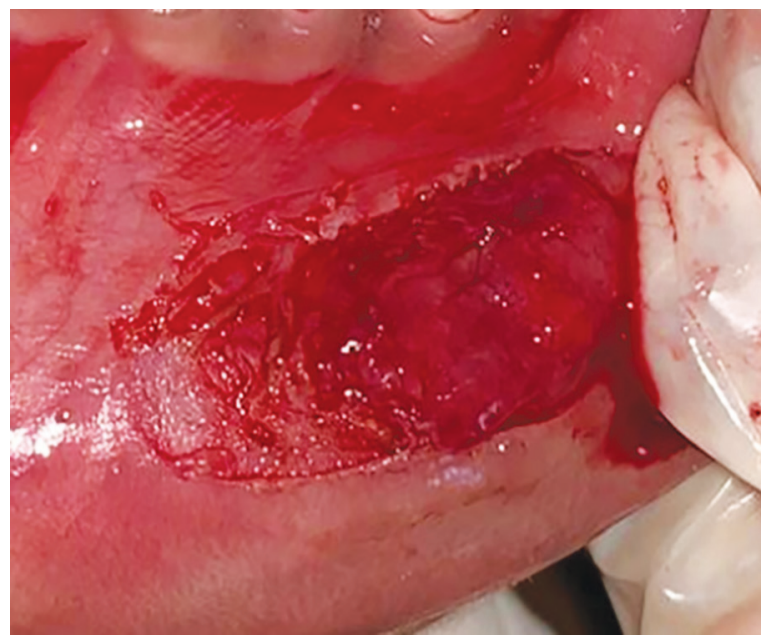

Fig. 4: Immediate postoperative

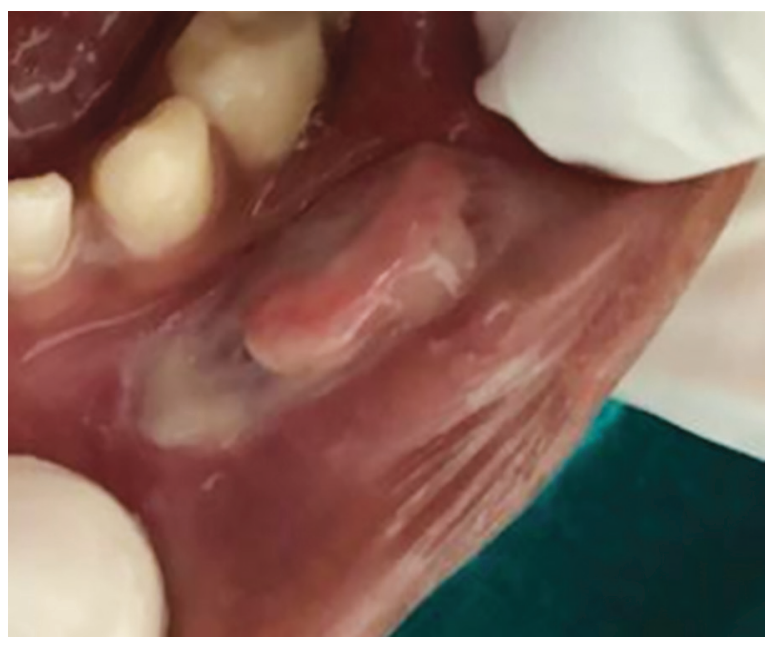

Fig. 5: After 1 week

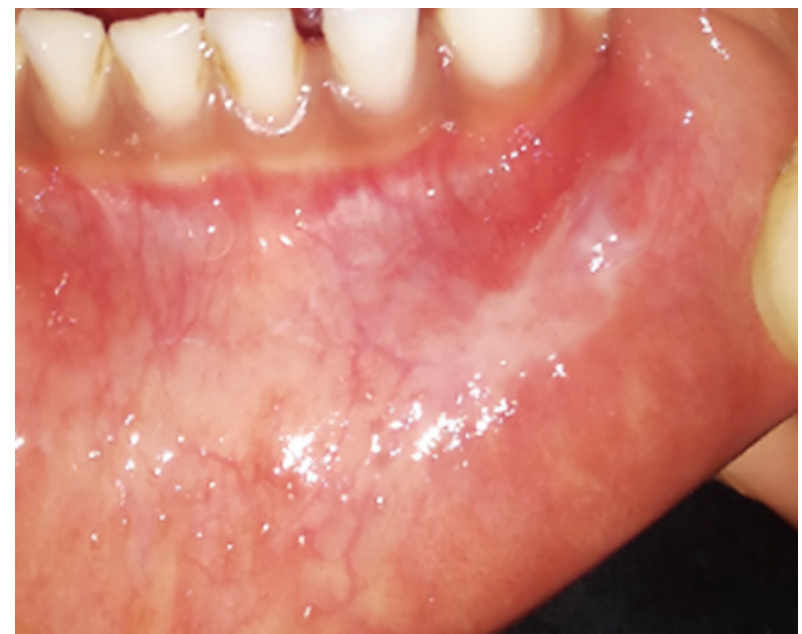

Fig. 6: Healing after 3 weeks 


\section{Discussion}

Mucocele is the second most common lesion in the oral cavity followed by irritational fibroma. Mucocele is a self-limiting mucuscontaining cyst of salivary glands commonly occurring in the oral cavity. With relatively rapid onset and fluctuating size, they can be the cause of discomfort and relapse. Mucoceles appear as domeshaped mucosal swellings with the characteristic accumulation of mucin. These lesions are usually asymptomatic and impart a bluish, transparent hue of variable size from 1-2 mm to several centimetres in dimension. ${ }^{9}$ The lower lip is the most common site of occurrence of mucocele followed by the buccal mucosa and floor of mouth. ${ }^{10}$ Depending upon the size and location of mucoceles, the various clinical features include external swelling and interference with mastication, swallowing, and speech, and discomfort might occur. ${ }^{9}$ The histopathologic examination of mucocele often reveals the formation of well-circumscribed, cyst-like space surrounded by granulation tissue and the presence of mucinophages in the collapsed wall of the granulation tissue.

The duration of the lesion is not constant and can last from few days to 3 years. ${ }^{11}$ The confirmatory diagnosis of oral mucocele is mainly based upon its location, history of trauma, rapid appearance, variations in size, bluish color, and consistency. On palpation, the lesion is often fluctuating in contrast to lipomas and tumors of minor salivary glands showing no fluctuation. ${ }^{12}$ There are various treatment aspects available for the management of mucocele: scalpel incision, complete surgical excision, marsupialization, micromarsupialization, intralesional injections of corticosteroids, cryosurgery, laser ablation, sclerosing agent, and electrocautery methods.

The laser is a very precise ablation instrument that offers certain advantages when compared to the scalpel. It causes minimal damage to adjacent tissues, especially the underlying muscle layers. ${ }^{13}$ Semiconductor diode lasers are available in different wavelengths such as $810-830 \mathrm{~nm}, 940 \mathrm{~nm}$, and $980 \mathrm{~nm}$. Diode lasers can be a useful alternative to larger surgical lasers such Er:YAG and $\mathrm{CO}_{2}$ lasers. They can give a well-defined cutting edge as well as coagulation and hemostasis during excision. ${ }^{14}$ Absorption of laser energy into the target tissue releases heat by the photothermal process, which further causes intra- and extracellular vaporization of cells with the resultant cellular explosion and tissue ablation. Delayed healing and a larger wound site may occur on prolonged laser application. On the contrary, the sealing of small diameter of vessels provides advantages like hemostasis during laser surgery. The area of adjacent coagulation ends with less bleeding at the surgical site.

\section{Conclusion}

Diode lasers have been effective in the treatment of mucocele as they offer minimum use of anesthesia, less bleeding, no scarring, no postoperative discomfort, more patient acceptance, and most importantly are precise and provide a sterilized field. Thus, diode lasers can be considered in the treatment of mucocele. Laser application makes it possible to reduce apprehension and fear in pediatric patients.

\section{References}

1. Ozturk K, Yaman H, Arbag H, et al. Submandibular gland mucocele: Report of two cases. Oral Surg Oral Med Oral Pathol Oral Radiol Endod. 2005;100:732-735. DOI: 10.1016/j.tripleo.2005.03.026.

2. Seifert $G$, Miehlke A, Haubrich J, et al. Diseases of the salivary glands. Stuttgart: Georg Thieme Verlag. 1986:91-100.

3. Sandrini FA, Sant'ana Filho M, Rados PV. Ranula management: Suggested modifications in the micromarsupialization technique. J Oral Maxillofac Surg. 2007;65:1436-1438. DOI: 10.1016/j. joms.2006.06.291.

4. Baramash HD. Mucoceles and ranulas. J Oral Maxillofac Surg. 2003; 61:369-378. DOI: 10.1053/joms.2003.50074.

5. Sarkar S, Karthick K. Ray of light in treatment of mucocele. Sch J Dent Sci 2017;4(2):55-57. DOI: 10.21276/sjds.2017.4.2.4.

6. Boneu Bonet F, Vidal Homs E, Maizcurrana Tornil A, et al. Submaxillary gland mucocele: Presentation of a case. Med Oral Patol Oral Cir Bucal. 2005;10:180-184. PMID: 15735552.

7. Pedron IG, Galletta VC, Azevedo LH, et al. Treatment of mucocele of the lower lip with diode laser in pediatric patients: Presentation of 2 clinical cases. Pediatr Dent. 2010;32:539-541. PMID: 21462769.

8. Pandey R, Reddy PK, Koppolu P, et al. Treatment of mucocele with diode laser. J Dent Lasers 2013;7(1):43-46. DOI: 10.4103/09762868.118457.

9. Re Cecconi D, Achilli A, Tarozzi M. Mucoceles of the oral cavity: a large case series (1994-2008) and a literature review. Medicina Oral, Patologia Oral y Cirugia Bucal 2010;15(4):e551-e556. DOI: 10.4317/ medoral.15.e551.

10. Chawla K, Lamba AK, Faraz F, et al. Treatment of lower lip mucocele with Er, Cr: YSGG laser: A case report." Journal of Oral Laser Applications. 2010;10(4);181-185.

11. Sinha R, Sarkar S, Khaitan T, et al. Nonsurgical management of oral mucocele by intralesional corticosteroid therapy. Int J Dent 2016. pp: 110-113. DOI: https://doi.org/10.1155/2016/2896748.

12. Agrawal S, Koirala B, Dali M, et al. Oral Mucocele: Various treatment modalities. Journal of Kathmandu Medical College 2018;7(25). DOI: https://doi.org/10.3126/jkmc.v7i3.22680.

13. Strauss RA. Lasers in oral and maxillofacial surgery. Dent Clin N Am 2000;44(4):851-873. DOI: https://doi.org/10.1016/j.cden.2004.06.005

14. Azma E, Safavi N. Diode laser application in soft tissue oral surgery J Lasers Med Sci 2013;4(4):206-211. PMID: 25606331. 